\title{
BIOPOLÍTICA E DOAÇÃO DE ÓRGÃOS: ESTRATÉGIAS E TÁTICAS DA MÍDIA NO BRASIL ${ }^{1}$
}

\author{
Lisiane Pruinelli², Maria Henriqueta Luce Kruse ${ }^{3}$
}

\footnotetext{
${ }^{1}$ Este artigo é resultado da dissertação - Mídia e doação de órgãos: a produção de sujeitos doadores, apresentada ao Programa de Pós-Graduação em Enfermagem da Universidade Federal do Rio Grande do Sul (UFRGS), em 2008.

${ }^{2}$ Mestre em Enfermagem. Enfermeira do Serviço de Enfermagem Cirúrgica e da Comissão Intra-Hospitalar de Doação e Transplantes de Órgãos e Tecidos para Transplantes do Hospital de Clínicas de Porto Alegre. Rio Grande do Sul, Brasil. E-mail: lisipru@hotmail.com

${ }^{3}$ Doutora em Educação. Professora do Programa de Pós-Graduação em Enfermagem da UFRGS. Rio Grande do Sul, Brasil. E-mail: kruse@uol.com.br
}

RESUMO: Tem como objetivo analisar as estratégias e as táticas que a mídia veicula para constituir sujeitos doadores de órgãos. O corpus de análise foi um jornal de grande circulação nacional, que é considerado o mais influente do Brasil. Estudo de natureza qualitativa, com abordagem exploratória, filiando-se aos estudos culturais em sua vertente pós-estruturalista, utilizando ferramentas propostas por Michel Foucault. A análise das matérias do jornal deixa emergir formas de poder que estabelecem verdades sobre a doação de órgãos. Consideramos que esses discursos são vistos como estratégia biopolítica que utiliza um emaranhado de táticas para conduzir a população, girando em torno das possibilidades da doação de órgãos.

DESCRITORES: Meios de comunicação. Transplantes de órgãos. Doadores de tecidos. Doadores de órgãos.

\section{BIOPOLITCS AND ORGAN DONATION: STRATEGIES AND TACTICS FROM BRAZIL'S MEDIA}

\begin{abstract}
This study aims to analyze the strategies and tactics that the Brazilian media links to constitute organ donor subjects. The corpus of analysis was a newspaper of wide national circulation that is considered the most influent of Brazil. This study is qualitative in nature with an exploratory approach and is associated with Cultural Studies in its post-structuralist slant, using tools proposed by Michael Foucault. The newspaper article analysis allows forms of power that establish truths about organ donation and what constitutes donor subjects to emerge. We consider that these speeches are seen as a biopolitical strategy that uses a tangle of tactics to conduct the population, revolving around the possibilities of organ donation.
\end{abstract}

DESCRIPTORS: Communication media. Organ transplantation. Tissue donors. Organ donors.

\section{BIOPOLÍTICA Y DONACIÓN DE ÓRGANOS: ESTRATEGIAS Y TÁCTICAS DE LOS MEDIOS DE COMUNICACIÓN DE BRASIL}

RESUMEN: El estudio tiene como finalidad analizar las estrategias y tácticas que los medios de comunicación transmiten para constituir sujetos donantes de órganos. El corpus de análisis fue un periódico de circulación nacional, que es considerado el más influyente de Brasil. Es un estudio cualitativo con enfoque exploratorio, relacionado a los Estudios Culturales en su vertiente postestructuralista, basado en las herramientas ofrecidas por Michel Foucault. El análisis de los artículos del periódico indica formas de poder que establecen verdades sobre la donación de órganos. Creemos que esos discursos son vistos como una estrategia biopolítica que utiliza una red de tácticas para conducir la población, en torno de las posibilidades de donación de órganos.

DESCRIPTORES: Medios de comunicación. Trasplantes de órganos. Donadores de tejido. Donadores de órganos. 


\section{INTRODUÇÃO}

"Doador e receptor. Unidos por um ato de amor". Esta frase abre o sítio da Associação Brasileira de Transplantes de Órgãos $(\mathrm{ABTO})^{1} \mathrm{e}$ representa o modo como as pessoas têm sido interpeladas para doar órgãos e tecidos. Tais modos de convencimento são geralmente associados a depoimentos de artistas que incitam a doar, poesias de autoria de possíveis doadores, relatos de pessoas que receberam órgãos e agradecem àqueles que os disponibilizaram. Assim, entendemos que a mídia influencia a vida das pessoas, vende ideias, dita modos de ser, reforça identidades, escolhe e aponta caminhos, veiculando discursos que nos atravessam e que vão nos constituindo como sujeitos. ${ }^{2}$ Esse modo de ver nos faz pensar de um jeito diferente a respeito das informações que incorporamos ao longo de nossas vivências no processo de transplante de órgãos e tecidos, uma vez que a possibilidade de transplantar órgãos está relacionada à decisão de doar, das próprias pessoas ou de suas famílias. Além disso, os transplantes só ocorrem porque existem pessoas que esperam por esses órgãos.

As cirurgias de transplantes de órgãos e tecidos ocorrem como resultado das transformações e das descobertas ocorridas na atenção à saúde no século XX. Já que para ocorrer um transplante se necessita de um doador - na maioria das vezes, um doador cadáver -, se instituiu a necessidade da discussão e da legitimação da morte cerebral, surgindo a demanda de se reconceitualizar a morte como uma forma de obter órgãos vitais, adequados para a realização desses transplantes. ${ }^{3}$ A legislação brasileira também se adequou a essas mudanças, tornando essa prática legal, através da determinação de quem são os doadores, quem pode autorizar a doação e quais documentos são exigidos para que ocorram doações.

Entendemos que o desenvolvimento de novas técnicas cirúrgicas e de preservação, a mudança na legislação, a mídia com suas campanhas, dando publicidade aos transplantes, bem como a vontade do doador e de sua família fazem emergir condições de possibilidade para que ocorram os transplantes de órgãos e tecidos em nossa sociedade. Dessa maneira, determinados saberes sobre a doação de órgãos tornam-se verdades no decorrer da história, inseridos em um campo largamente contestado, de lutas e de relações de poder que possibilitam sua construção. Tais discursos, que constituem saberes sobre os transplantes de órgãos, contribuem para o fazer da enfermagem, para o ensino e a pesquisa em saúde, em especial para aqueles que trabalham e produzem novos saberes relacionados aos transplantes de órgãos. Assim, este estudo tem como objetivo analisar as estratégias e as táticas que a mídia veicula para constituir sujeitos doadores de órgãos.

\section{A TRAJETÓRIA METODOLÓGICA}

Esta pesquisa é de natureza qualitativa, com abordagem exploratória. Filia-se aos estudos culturais, especialmente em sua vertente inglesa, que procuram compreender a complexidade dos eventos e dos processos nos quais as identidades são formadas e transformadas, em que práticas sociais são vistas como cultura. Os textos culturais são "[...] práticas de representação, inventam sentidos que circulam e operam nas arenas culturais onde o significado é negociado e as hierarquias estabelecidas". ${ }^{4: 38}$ A mídia é um espaço de circulação de discursos dotados de autoridade, capazes de vender ideias, ditar modos de ser, reforçar identidades, escolher e apontar caminhos. ${ }^{5}$

O corpus de análise da pesquisa é a Folha de São Paulo, o jornal de maior tiragem e circulação do Brasil, considerado o mais influente, e que foi o primeiro jornal on-line do país. Realizamos uma leitura interessada dos textos do jornal a partir do ano de 1997, quando passou a ser disponibilizado na internet e, concomitantemente, ocorreram grandes mudanças no processo de doação de órgãos no Brasil. Para localizar as matérias, utilizamos os descritores transplante de órgãos e doação de órgãos, que permitiram selecionar 513 reportagens, no período de 1997 até outubro de 2008. Após a leitura das mesmas, selecionamos 64 reportagens que iam ao encontro de nossa proposta de estudo.

Para a análise textual, olhamos para os discursos do jornal a partir do referencial de Michel Foucault, utilizando ferramentas como discurso, governamento e biopoder. Analisamos os textos como monumentos para a construção de sujeitos doadores de órgãos, já que servem para lembrar e pensar, são como um ponto de partida ao pensamento e à ação, para ser um lembrete e uma advertência. ${ }^{6}$ Em toda a sociedade, a produção de discurso é, ao mesmo tempo, controlada, selecionada, organizada e redistribuída, e nem todos têm o direito de dizer tudo, falar em qualquer circunstância e sobre qualquer coisa, e ninguém está autorizado a fazê-lo se não satisfizer a certas exigências, determinando as condições de seu funcionamento. ${ }^{7}$ Por outro lado, aqueles 
que detêm o saber estão autorizados para falar sobre determinado assunto, são consideradas experts. Partimos da suposição de que os discursos das matérias do jornal disciplinam e governam sujeitos através da expertise de seus escritos, num meio que se torna público, no qual a vida do indivíduo e da população são repetidamente rediscutidas e repensadas. Olhamos para tais discursos como instrumentos de poder em que se permite o controle minucioso das operações do corpo e a sujeição constante de suas forças.

Esse modo de governo faz uso de uma lógica na qual cada um é, simultaneamente, alvo de múltiplas interpelações e também especialista, supostamente sabedor do que lhe convém. Assim, esses discursos são veiculados num espaço, o jornal, em que constituem uma arena de verdade e saber, atuando na constituição de sujeitos, compondo uma arte de governar. ${ }^{8}$ O governo dos sujeitos lhes proporciona artefatos suficientes para que, ao serem sabedores de como se dá um processo de transplantes, seus condicionantes, seus benefícios e seus possíveis obstáculos tenham conhecimento abrangente sobre o assunto e se sintam na posição de tomar a decisão considerada verdadeira.

No século XVIII, surge a biopolítica, que tende a tratar a população como um conjunto de seres vivos e coexistentes, que apresentam traços biológicos e patológicos particulares, e que, por conseguinte, dizem respeito a técnicas e a saberes específicos. ${ }^{9}$ Entendemos que os discursos do jornal se dirigem à população, os leitores do jornal, como sujeitos de necessidades, de aspirações, conscientes daquilo que querem e inconscientes em relação àquilo que se quer que eles façam. Nesse conceito, aplica-se uma espécie de poder regulador que procura intervir na vida dos seres humanos, um poder que atua no sentido de fazer viver, controlar os possíveis acidentes e aumentar o tempo de vida, deixando a morte de lado. É a partir desses sentidos que podemos entender as articulações que tornam efetivos os transplantes de órgãos, sua condição de possibilidades, bem como as ferramentas necessárias para gerir o corpo individual e a população, fazendo com que sujeitos assumam certas condutas e não outras.

Para analisar os discursos veiculados no jornal e mostrar como estes governam sujeitos, utilizamos os termos estratégia e tática, conforme estabelecidos por Michel Foucault. A primeira é descrita como continuação da política, como meio fundamental para prevenir o distúrbio, em que as nações defrontam suas forças econômicas e demográficas, e o segundo, utilizado como arte de construir manobras de controle dos corpos e das forças individuais, forças que se encontram majoradas por sua combinação calculada. Utilizamos tais termos como numa guerra-política, na qual "é a estratégia que permite compreender a guerra como uma maneira de conduzi-la entre os Estados [...] e é a tática que permite compreender o exército como um princípio para manter a ausência de guerra na sociedade civil".${ }^{10: 142}$

\section{DAS ESTRATÉGIAS E DAS TÁTICAS VEICULADAS}

Observamos que, no decorrer dos anos, o tema dos transplantes e das doações de órgãos no Brasil e no mundo foi abordado recorrentemente pelo jornal, utilizando um aparato numérico que impressiona, fazendo um jogo que se entrecruza e que alcança a vida das pessoas que o leem. Taxas de doações, de transplantes, de desperdício de órgãos, de mortes dos que esperam na fila de transplantes são tratados como fenômenos que podem ser medidos, possibilitando realizar um mapeamento da população. Esse controle dos fenômenos produz um panorama dos transplantes no Brasil, de sua evolução no decorrer dos anos, da melhora da sobrevida dos transplantados, visando a identificar as doenças como fatores permanentes, mostrando os doentes e suas doenças, a perda de suas forças, suas limitações econômicas, seu convívio com a doença. Ojornal retoma esses fenômenos nas matérias e indica a necessidade de se ter mais doadores e diminuir a fila de espera, a fim de que ocorram mais transplantes. As reportagens do jornal mostram as doenças como fenômenos da população, que não se abatem brutalmente sobre a vida, como as epidemias, mas como uma morte permanente, que se introduz sorrateiramente na vida, corroendo-a, diminuindo-a e enfraquecendo-a. ${ }^{11}$ "[...] essa taxa de mortalidade é muito difícil de mudar. Talvez a lista única ajude" . ${ }^{12}$ “[...] o problema é que a demanda é muito maior que a oferta. [...] 10 mil mortes encefálicas por ano [...] só a metade é notificada [...] se somarmos o aviso tardio [...] o desperdício pode ser ainda maior [...] dos órgãos captados, $40 \%$ são descartados [...] o aproveitamento real é de $10 \%[\ldots]^{\prime \prime} .^{13}$

Os títulos das reportagens já anunciam o que o texto vai abordar, de forma direta e impactante, marcando o que é bom e o que é ruim. O que é bom é referido como crescimento, recorde, subida, sempre relacionados a dados estatísticos mostrados e 
comentados por algum expert. Por outro lado, o que é mau é apresentado como falência, desperdício, morte e quedas consecutivas no número de transplantes, quando as doações não são as esperadas. As reportagens abordam dados que se repetem; há um sobe e desce dos números no decorrer dos anos, sendo enfatizado tanto o recorde como a queda. "Transplantes de órgãos batem recorde no Brasil". ${ }^{14}$ " $40 \%$ morrem na fila de espera". ${ }^{12}$ "País desperdiça $50 \%$ dos órgãos para transplante" ${ }^{13}$

As mudanças ocorridas na década de 1990, relativas à política de transplantes de órgãos e tecidos no Brasil, configuram o que aqui consideramos uma estratégia biopolítica, uma vez que se propõe a conduzir o processo de transplantes. Entre 1997 e 2001, ocorreram mudanças na legislação, tidas pelo jornal como "as grandes mudanças". Foi nesse período que se deu a transição legal encerrada com a aprovação da Lei de Transplantes, em que a decisão de doar passou a ser de responsabilidade da família do paciente que se encontra em morte encefálica. É importante destacar tais fatos, pois foi nesse período que se constituiu o que se pode chamar de rede de transplantes no Brasil, com a criação do Sistema Nacional de Transplantes (SNT), das Centrais de Notificação, Captação e Distribuição de Órgãos (CNCDO), em nível nacional e estadual, bem como o Cadastro Técnico Único, a fila única de espera de órgãos. A criação desses mecanismos tornou possível o controle minucioso do que acontece com as pessoas que têm a possibilidade de doar e aquelas que necessitam de um transplante de órgãos.

O SNT, como estratégia dessa biopolítica, utiliza-se do que consideramos a grande tática, a fila única, que permite compreender o processo e mantê-lo visível. Essa nova tática vigia os doentes que estão inclusos com seus exames, hierarquizando os que têm valores piores e melhores, que poderão subir ou descer de posição, possibilitando que sejam transplantados ou não. A criação da fila única buscou formar quadros vivos que transformam as multidões confusas, no caso os pacientes que aguardavam transplante, em multiplicidades organizadas. Com isso, ocorreu um maior conhecimento sobre o processo de transplantes, do hospital em que o paciente estava inscrito, da equipe que seria sua transplantadora, do centro transplantador, da gravidade do paciente. Ao integrar a fila única, os doentes sabem sua posição, seu lugar em relação aos outros. Desse modo, podem ser controlados e vigiados pelos demais pacientes, pelos médicos e pelo centro transplantador, pela CNCDO, pelo SNT, pois essa classificação permite observar, controlar e regular a circulação dessas pessoas, estabelecendo um quadro econômico possível de detectar presenças e ausências, constituindo um registro geral e permanente dos doentes e das equipes envolvidas.

A visibilidade do processo do transplante é possível a partir dessa técnica. Assim, fica evidente a equipe transplantadora que transplanta mais ou menos, quantos morrem, quantos recebem órgãos, quantas doações são realizadas, quantos órgãos são aproveitados, quem não segue a lei, quem permite furar a fila e quem desperdiça órgãos. Tal esquadrinhamento torna possível o controle estatístico do processo de transplantes, visto como incentivo a novas doações, como mostra o jornal: "O uso da lista única, pública e eficiente na destinação dos órgãos, coibindo desperdícios ou desvios, é o melhor estímulo para aumentar o número de doadores no país". ${ }^{15}$

Entendemos que a biopolítica utiliza e se encaixa nesses instrumentos disciplinares para dirigir a vida das pessoas, para coordenar os tratamentos, centralizar as informações, normalizar os saberes, introduzindo mecanismos mais sutis, economicamente mais racionais, mecanismos de seguridade. A biopolítica cuida da população, dos prováveis doadores e dos que aguardam por um órgão, considerando-os como fenômenos coletivos, e fazendo previsões, estimativas estatísticas de medições globais. Como consequência, estabelece mecanismos reguladores que vão equilibrar, manter uma média, otimizar de maneira que se obtenham estados globais de equilíbrio, de regularidade, de levar em conta a vida e de processos de regulamentação, o que consiste em fazer viver. ${ }^{11}$

A presença constante dos experts no jornal, apresentando números que evidenciam o que ocorre em termos de doação de órgãos no Brasil e no mundo, faz com que se estabeleça uma comparação do país com outros considerados mais avançados, os quais seria desejável imitar: "[...] mas o número de transplantes realizados no país fica longe do ideal; [...] o Brasil tem apenas 3,5 doadores por milhão de habitantes, contra 29, em média, na Espanha". ${ }^{16}$

O presidente da ABTO comenta o crescimento no número de transplantes registrado em 1998 com relação ao ano anterior, e que foi o primeiro aumento registrado desde 1993: " [...] embora não indique melhora substancial na situação de escassez de órgãos, dá ensejo a algum alento [...] o número se mostra ainda desapontadoramente baixo [...] com o pequeno progresso [...] ocorrem parcas 3,5 
doações [...] listas de espera que só fazem aumentar, tanto em candidatos como em agonia". ${ }^{17}$ Os dados são abordados com palavras que impactam o leitor, utilizando termos como substancial, ensejo, parcas, pequeno progresso e agonia, que revelam e nomeiam a situação dos transplantes no país.

É nesse jogo de números que as reportagens interpelam o leitor, mostrando as verdades do mundo dos transplantes. Nos primeiros anos após a implementação do novo sistema de registro, o jornal trouxe experts para comentar os dados que eram encontrados no Brasil, apontando as pessoas que aguardavam, o número de doadores, as projeções para o ano em comparação com os anteriores: “[...] a projeção para este ano [...] é que os doadores cheguem a 3,6 para cada 1 milhão de habitantes. Em 98 e 97, foram 3 e 2,8, respectivamente"..$^{18}$ Os dados referem-se ao período após a implantação do SNT, que possibilitou o registro, o controle e a vigilância do que acontece.

O acúmulo de informações numéricas proporcionado pelo controle implantado permite que o discurso veiculado pelo jornal seja mais direcionado, enfatizando os melhores e os piores resultados dos dados de doações e transplantes, destacando um período de queda que ocorreu entre 2004 e 2007, quando o responsável pelo Registro Brasileiro de Transplantes, outro expert, comenta: “[...] o país está chegando a resultados iguais aos de 1998. Tudo o que avançou nesses anos está se perdendo agora. A nossa expectativa era crescer pelo menos 0,5 (doadores por milhão de habitantes) por ano $[\ldots]^{\prime \prime}{ }^{19}$

O ano de 2004 é lembrado em várias reportagens como o ano em que se bateu o recorde histórico em doações no Brasil. Para marcar tal data são utilizados números que se repetem nas reportagens: "[...] a marca ainda é inferior à de $2005(6,3)$ e à de $2004(7,2)$, a maior marca até hoje. Na Espanha, o índice chega a $35[. .].]^{\prime 2}{ }^{20}$ Os dados aparecem como taxas, números totais, número por milhão de habitantes, para mostrar o sobe e desce das doações. Esses números são utilizados pelos experts para abordar os fatores que contribuem para o aumento ou a diminuição dos eventos, produzindo uma rede de informação sobre pacientes e potenciais doadores, produzindo dados que atingem a população, mostrando o quanto se gasta e o quanto se investe.

As reportagens do jornal veiculam os altos custos para a manutenção dos pacientes que aguardam por um transplante, os investimentos necessários, os já executados para que seja possível realizar transplantes e contrastam com o que está acontecendo: " [...] crise da saúde no país [...] estrutura horrível dos hospitais, onde o atendimento é péssimo [...] falta de infraestrutura. [...] a falta de estrutura para a captação de órgãos [...]". ${ }^{19}$ Outros problemas, como financiamento, "[...] conspiram para tornar o transplante não uma esperança de uma vida melhor, mas um martírio [...]". ${ }^{21}$

Altos investimentos realizados pelo governo contrariam os comentários quanto às condições hospitalares brasileiras que são tidas como péssimas, sem estruturas para captação de órgãos e são desfavoráveis à esperança de quem vive o martírio da espera de um órgão. "[...] o governo aumentou [...] passando de $\mathrm{R} \$ 343$ milhões em 2003 para $\mathrm{R} \$$ 400 milhões neste ano $[\ldots]]^{\prime 2} .{ }^{22}$ As falas expressam o aumento do orçamento para os transplantes e comparam os custos com cada paciente em diálise no Brasil e na Espanha: “[...] os gastos com diálise ultrapassam $R$ \$ 1,1 bilhão, contra $\mathrm{R} \$ 600$ milhões de todo o sistema de transplantes. Há mais do que razões humanitárias, como se vê, para considerar o modelo espanhol com atenção [...]". ${ }^{23}$ Tais argumentos apresentam a manutenção dos pacientes em lista de espera como mais onerosa do que a realização de transplantes. Desse modo, os discursos do jornal exercem procedimentos que se autocontrolam, que funcionam como princípios de classificação, de ordenação e de distribuição, colocando em jogo o poder e o desejo das pessoas envolvidas e dos dados estatísticos sobre transplante de órgãos.

Podemos entender que o controle estatístico dos transplantes de órgãos, que se torna visível nas matérias do jornal, parece ser reivindicado para servir de objetivo à vida como objeto das lutas políticas. "[...] cabe às autoridades perseverar, esclarecendo o público sobre a importância da doação e aparelhando hospitais para garantir aproveitamento máximo dos órgãos salvadores $[\ldots]^{\prime \prime} .{ }^{17}$ "[...] pessoas já morrem muito amiúde de forma tola no Brasil; se essas mortes puderem reverter em vida para outros, menos mal [...]". ${ }^{21}$ "O 'direito' à vida, ao corpo, à saúde, à felicidade, à satisfação das necessidades, o 'direito', acima de todas as opressões ou 'alienações', de encontrar o que se é e tudo o que se pode ser [...]". 24:158

O desenvolvimento dos conhecimentos a respeito da vida em geral, das observações e medidas visando à vida e a sobrevivência das pessoas contribuiu para um relativo domínio sobre a mesma, o que afasta alguns da iminência da morte. ${ }^{24} \mathrm{~A}$ biopolítica determina que a vida e seus mecanismos entrem no domínio dos cálculos 
explícitos, fazendo do poder-saber um agente de transformação da vida humana, que a organiza e a amplia; enfim, procedimentos de poder e saber que controlam e modificam os processos da vida. Desse modo, o ser humano ocidental aprende a ser uma espécie viva num mundo vivo, ter um corpo, condições de existência, probabilidade de vida, saúde individual e coletiva. O biológico, então, se reflete no político, já que viver não significa emergir de tempos em tempos, viver, entra no campo de controle do saber e de intervenção do poder.

\section{CONSIDERAÇÕES FINAIS}

Os discursos veiculados no jornal destacam os modos pelos quais se constituem sujeitos doadores de órgãos, isto é, discursos que conduzem a conduta das pessoas, modelando-as, guiando-as e governando-as. Assim, constituem uma estratégia da biopolítica, que utiliza um emaranhado de táticas para conduzir a população, girando em torno das possibilidades de doar e receber órgãos.

A implantação da fila única, a legislação que se adequou aos interesses da sociedade, o controle estatístico, as campanhas, as expertises usadas nos escritos do jornal são práticas que deram visibilidade ao sistema de transplantes, evidenciando discursos que visam a informar, esclarecer e convencer os leitores a doarem seus órgãos ou os de seus familiares. Desse modo o que pretendemos analisar neste estudo não foi o processo de doação de órgãos e transplante, mas as estratégias e as táticas que a mídia veicula. Com isso, procuramos mostrar como os excertos das reportagens do jornal analisadas interpelam os seus leitores a fim de que se tornem sujeitos doadores de órgãos. Estudos desse tipo contribuem para o fazer da enfermagem, já que mostram outros modos de olhar para temáticas que parecem já estar constituídas na formação do sujeito enfermeiro. Entendemos que tais discursos, dotados de verdade, interpelam os sujeitos que leem o jornal, não deixando margem para não doar, pois os escritos determinam que doar é a coisa certa a fazer, produzindo um discurso do qual é quase impossível escapar.

\section{REFERÊNCIAS}

1. Associação Brasileira de Transplante de Órgãos [internet]. São Paulo (SP): ABTO; 2007 [acesso 2007 Nov 25]. Disponível em: http:/ / www.abto.org.br

2. Fischer RMB. Mídia, máquinas de imagens e práticas pedagógicas. Rev Bras Educ. 2007 MaiAgo;12(35):290-99.
3. Vargas MA, Ramos FRS. A morte cerebral como o presente para a vida: explorando práticas culturais contemporâneas. Texto Contexto-Enferm. 2006 JanMar;15(1):137-45.

4. Costa MV, Silveira RH, Sommer LH. Estudos culturais, educação e pedagogia. Rev Bras Educ. 2003 Mai-Ago; 23: 36-61.

5. Frow J, Morris M. Estudos culturais. In: Denzin N. O planejamento da pesquisa qualitativa: teorias e abordagens. Porto Alegre (RS): Artmed; 2006. p. 315-44.

6. Kruse MHL. Os poderes dos corpos frios: das coisas que se ensinam às enfermeiras. Brasília (DF): ABEn; 2004.

7. Foucault M. A ordem do discurso. São Paulo (SP): Loyola; 2006.

8. Foucault M. Microfísica do poder. Rio de Janeiro (RJ): Graal; 2007.

9. Foucault M. Resumo dos cursos do Collège de France (1970-1982). Rio de Janeiro (RJ): Jorge Zahar; 1997.

10. Foucault M. Vigiar e punir: história da violência nas prisões. Petrópolis (RJ): Vozes; 2007.

11. Foucault M. Em defesa da sociedade: curso no Collège de France (1975-1976). São Paulo (SP): Martins Fontes; 1999.

12. Martins L. $40 \%$ morrem na fila dos transplantes. Folha de São Paulo [online] 1997 Jul 7. [acesso 2008 Ago 6]. Disponível em: http:/ / www1.folha.uol.com. br/fsp/cotidian/ff090724.htm

13. Collucci C. País desperdiça $50 \%$ dos órgãos para transplante. Folha de São Paulo [online] 1997 Dez 23. [acesso 2008 Ago 4]. Disponível em: http:/ /www1. folha.uol.com.br/fsp/cotidian/ff2312200701.htm

14. Flor A. Transplante de órgãos bate recorde no Brasil. Folha de São Paulo [online]. 2004 Dez 15. [acesso 2008 Set 5]. Disponível em: http:/ / www1.folha.uol. com.br/fsp/cotidian/ff1512200423.htm

15. Vida aos transplantes. Folha de São Paulo [online] 1998 Jul 31. [acesso 2008 Ago 21]. Disponível em: http://www1.folha.uol.com.br/fsp/opiniao/ fz31079803.htm

16. Russo N. Transplantes crescem $12,5 \%$ em 98 . Folha de São Paulo [online] 1999 Jan 19. [acesso 2008 Set 5]. Disponível em: http:/ / www1.folha.uol.com.br/ fsp/cotidian/ff19019920.htm

17. Mais transplantes. Folha de São Paulo [online] 1999 Jan 20. [acesso 2008 Ago 21]. Disponível em: http:/ / www1.folha.uol.br/fsp/opiniao/fz20019903.htm

18. Floresta C. Doação cresce, mas é menor que o esperado. Folha de São Paulo [online] 1999 Set 21. [acesso 2008 Ago 21]. Disponível em: http:/ / www1. folha.uol.com.br/fsp/cotidian/ff2109199917.htm

19. Reis T, Pichonelli M. Doação de órgãos no Brasil cai pelo terceiro ano consecutivo. Folha de São Paulo [online] 2007 Set 3. [acesso 2008 Ago 21]. Disponível 
em: http://www1.folha.uol.com.br/fsp/cotidian/ ff0309200719.htm

20. Pichonelli M, Reis T. Após 2 anos, sobe $n^{\circ}$ de transplantes no país. Folha de São Paulo [online] 2008 Mar 12. [acesso 2008 Ago 6]. Disponível em: http://www1.folha.uol.com.br/fsp/cotidian/ ff1203200813.htm

21. Faltam órgãos. Folha de São Paulo [online] 2000 Jun 26. [capturado 2008 Ago 21]. Disponível em: http://www1.folha.uol.com.br/fsp/opiniao/ fz2006200002.htm
22. Número de transplantes deverá atingir recorde em 2004 no Brasil. Folha de São Paulo [online] 2004 Jul 20. [acesso 2008 Ago 27]. Disponível em: http://www1.folha.uol.com.br/fsp/cotidian/ ff2007200418.htm

23. Transplantes à espanhola. Folha de São Paulo [online] 2007 Dez 30. [acesso 2008 Ago 21]. Disponível em: http://www1.folha.uol.com.br/ fsp/opiniao/fz3012200702.htm.

24. Foucault M. História da sexualidade I: a vontade de saber. Rio de Janeiro (RJ): Graal; 2006. 